\title{
Real-Time Load Variability Control Using Energy Storage System for Demand-Side Management in South Korea
}

\author{
Kyo Beom Han ${ }^{1}$, Jaesung Jung ${ }^{2}\left(\mathbb{C}\right.$ and Byung $O$ Kang ${ }^{1, *}$ \\ 1 Department of Electrical Engineering, Dong-A University, Saha-gu, Busan 49315, Korea; ryqja18@donga.ac.kr \\ 2 Department of Energy Systems Research, Ajou University, Suwon 16499, Korea; jjung@ajou.ac.kr \\ * Correspondence: bokang@dau.ac.kr
}

Citation: Han, K.B.; Jung, J.; Kang, B.O. Real-Time Load Variability Control Using Energy Storage System for Demand-Side Management in South Korea. Energies 2021, 14, 6292. https://doi.org/10.3390/en14196292

Academic Editor: Marco Pau

Received: 13 August 2021

Accepted: 30 September 2021

Published: 2 October 2021

Publisher's Note: MDPI stays neutral with regard to jurisdictional claims in published maps and institutional affiliations.

Copyright: (c) 2021 by the authors. Licensee MDPI, Basel, Switzerland. This article is an open access article distributed under the terms and conditions of the Creative Commons Attribution (CC BY) license (https:// creativecommons.org/licenses/by/ $4.0 /)$.

\begin{abstract}
In today's power systems, the widespread adoption of smart grid applications requires sophisticated control of load variability for effective demand-side management (DSM). Conventional Energy Storage System (ESS)-based DSM methods in South Korea are limited to real-time variability control owing to difficulties with model development using customers' load profiles from sampling with higher temporal resolution. Herein, this study thus proposes a method of controlling the variability of customers' load profiles for real-time DSM using customer-installed ESSs. To optimize the reserved capacity for the proposed maximum demand control within ESSs, this study also proposes a hybrid method of load generation, which synthesizes approaches based on Markov Transition Matrix (MTM) and Artificial Neuron Network (ANN) to estimate load variations every $15 \mathrm{~min}$ and, in turn reserve capacity in ESSs. The proposed ESS-based DSM strategy primarily reserves capacity in ESSs based on estimated variation in load, and performs real-time maximum demand control with the reserved capacity during scheduled peak shaving operations. To validate the proposed methods, this study used load profiles accumulated from industrial and general (i.e., commercial) customers under the time-of-use (TOU) rate. Simulation verified the improved performance of the proposed ESS-based DSM method for all customers, and results of KolmogorovSmirnov (K-S) testing indicate advances in the proposed hybrid estimation beyond the stand-alone estimation using the MTM- or ANN-based approach.
\end{abstract}

Keywords: demand-side management (DSM); energy storage system (ESS); maximum demand control; synthetic load generation; peak shaving

\section{Introduction}

Around the world, smart grids have been widely adopted to respond to environmental problems, enhance energy efficiency, and improve electric services [1]. Smart grids are also considered to improve stability in power systems amid the expansion of small-scale renewable energy resources (RES) and the increase of unpredictable power demand such as charging electric vehicles [2,3]. Using various smart grid applications, system operators have begun replacing supplier-centered demand-side management (DSM) with customercentered DSM [4], which the operators have encouraged by providing specialized devices capable of load management and incentivizing participation via electricity tariff structures developed for DSM [5].

DSM is typically applied in three ways: peak shaving, peak shifting, and valley filling [6,7]. For one, peak shaving decreases seasonal and hourly peak demand for electricity according to the use of maximum demand controllers, emergency blackout, the remote control of heating and cooling in buildings, and other conditions. Peak shifting reduces peak demand by shifting demand during on-peak times to off-peak times, a thermal storage heating and cooling system using midnight power service is a good example. Last, valley filling increases demand during off-peak times as a means to improve the system's utilization. Using those applications, DSM has improved the stability and reliability of 
power systems in North America and the Persian Gulf, as well as reduced carbon emissions in China [8]. Policies for DSM have also been established to reduce carbon emissions, improve energy efficiency, and popularize demand response in the United Kingdom [9].

Energy storage systems (ESS) can be applied in DSM to store energy during certain times and provide the stored energy immediately if necessary [10]. In that way, customerinstalled ESSs can replace conventional maximum demand controllers installed for DSM, which perform peak shaving or shifting on the customers' side to effectively control their electricity loads under a time-of-use (TOU) tariff structure. For DSM, customer-installed ESSs collect information about customers' loads, tariff rates, and the status of their devices such as batteries and power conditioning systems (PCS). Based on that information, ESSs predict the profiles of customers' future loads for the operational scheduling of charging and discharging.

Among previous studies that have proposed ESS-based DSM methods for customers using TOU tariffs, some have introduced estimating the optimal capacity of ESSs to reduce the annual peak power used by industrial, commercial, and residential customers [11-13]. Kim et al. have proposed an optimal operational method using multiple ESSs for high demand customers that they validated using real-time control [14]. Kodaira et al. proposed an operational strategy for ESSs to allow peak shaving according to the probabilistic prediction of loads to minimize the peak effects in distribution [15]. Yoon et al. have applied a real-coded genetic algorithm for the efficient scheduling of ESS charging and discharging in order to improve the feasibility of the systems [16]. Kang et al. proposed another ESS operational strategy that involves participating in the demand response (DR) market and self-saving operations for ESSs [10]. Lee et al. developed an ESS scheduling algorithm that integrates self-saving and participation in DR based on predicted load profiles [17]. Jeong et al. developed adaptive ESS operation strategies based on the classification of different customers' loads [18].

However, ESS-based DSM methods have been limited in real-time control of variability in load. Several researches have introduced that the widespread adoption of smart grid applications in distribution such as distributed RESs and electric vehicles causes severe variability in load, which can deteriorate the quality of power [19-23]. To develop ESSready scheduling algorithms capable of real-time control against load variations, it is required to acquire information including real-time load variability for an acceptable duration. Unfortunately, the ESS-based DSM methods have been developed with reference to samples of customers' historical load profiles representing an accumulated duration, which has been $15 \mathrm{~min}$ in South Korea and cannot show real-time load variability This limitation brings the developed method to schedule ESS to discharge fixed amounts of power during such accumulated durations. To overcome such limited resolution, effective estimation techniques capable of predicting load variations are needed that can generate synthetic load profiles with higher resolutions.

To estimate variability in power systems, several studies have proposed synthetic data generation models. Among them, Ngoko et al. applied a Markov model for the synthesis of high-resolution data about solar radiation [24]. Kang and Tam generated synthetic sequences of proposed characterization parameters of measured solar data using a Markov approach and verified the similarity between observed and synthetic sequences using the Kolmogorov-Smirnov (K-S) test [25]. Pillai et al. proposed synthetic load generation to reduce the uncertainty of power system designs for a newly developed area; to that end, they applied an artificial neuron network (ANN) model to estimate synthetic loads utilizing corresponding meteorological data representing the targeted area [26]. Lastly, Ekonomou et al. utilized temperature, humidity, and other meteorological parameters to develop an ANN-based estimation model for synthetizing sequences of demand and more accurate estimation via training, verification, and testing processes [27]. All of those methods of estimating variability in power systems developed with stochastic or artificial algorithms provide practical guidance for effectively estimating load variation within the sampling limitation. 
Against that background, this study here proposes an ESS-based DSM approach that enables the simultaneous maximum demand control with variability in customers' loads within 15 min during peak shaving. To optimize the reservation of capacity given the proposed maximum demand control in ESSs, this study also proposes a new method concerning the generation of synthetic loads to estimate 1-min load variations during 15 min periods with a hybrid model developed by combining the estimation models of Markov transition matrixes (MTM) and the ANN algorithms. The proposed methods were simulated with load profiles accumulated by industrial and general (i.e., commercial) customers, for results demonstrating the advanced performance of the proposed methods compared with conventional approaches.

In what follows, Section 2 introduces the conventional ESS-based means of control for DSM under TOU tariff structures. Next, Section 3 proposes an ESS-based method for controlling maximum demand minute-by-minute and introduces a hybrid model for synthesizing load generation to effectively estimate minute-based variations from a sample of 15-min load profiles. Section 4 presents our simulations of the proposed methods based on load profiles accumulated by different customers, after which Section 5 concludes the work.

\section{Conventional ESS Control for DSM}

\subsection{TOU Tariff Structure}

Korea Electric Power Corporation (KEPCO) provides TOU tariff structures to industrial and general (i.e., commercial) customers with different electricity rate schedules for season and time, shown in Table 1 [5]. The schedules are classified into winter and nonwinter seasons (i.e., spring, summer, and fall), and 24-h weekday schedules for each season are classified into three load-based phases: off-peak, mid-peak, and on-peak. On Saturdays, the on-peak load is replaced by the mid-peak load, and on Sundays and holidays, the mid-peak and on-peak loads are replaced by the off-peak load. Table 2 presents examples of electricity rate tables for industrial and general customers provided by KEPCO [5], in which service refers to customers' contract demand, $B$ indicates a demand of $300 \mathrm{~kW}$ or more, and High-voltage A and High-voltage B indicate the voltages of 3.3-66 kV and 154 $\mathrm{kV}$, respectively. With rates differentiated by demand and usage, the monthly charges for industrial and general customers in South Korean won (KRW) can be calculated as:

$$
\text { Monthly Charge }=1.137 \times\left\{C_{\text {demand }} \times P_{\text {peak }}+\sum\left(C_{\text {usage }} \times E_{\text {usage }}\right)\right\}
$$

where 1.137 is the value-added tax (VAT) of $10 \%$ plus so-called "Electric Power Industry Basis Fund" of $3.7 \%$; $C_{\text {demand }}$ is the demand charge rate in KRW $/ \mathrm{kW} ; P_{\text {peak }}$ is the annual peak of customers in $\mathrm{kW}$; and $C_{\text {usage }}$ and $E_{\text {usage }}$ are the usage charge rates in $\mathrm{KRW} / \mathrm{kWh}$ and energy usages in $\mathrm{kWh}$ at the corresponding hours, respectively. $P_{\text {peak }}$ is decided in 15-min intervals during mid-peak and on-peak loads, and valid for a year after a new peak appears. Because this new peak can significantly increase the monthly charge due to the higher rate on the demand charge $\left(C_{\text {demand }}\right)$, real-time control of load variability is needed to restrain annual peaks of customers.

Table 1. Electricity rate schedules for season and time [5].

\begin{tabular}{ccc}
\hline Classification & $\begin{array}{c}\text { Spring, Summer, and Fall } \\
\text { (1 March-31 October) }\end{array}$ & $\begin{array}{c}\text { Winter } \\
\text { (1 November-28 February) }\end{array}$ \\
\hline Off-peak & $23: 00-09: 00$ & $23: 00-09: 00$ \\
\hline \multirow{2}{*}{ Mid-peak } & $09: 00-10: 00$ & $09: 00-10: 00$ \\
& $12: 00-13: 00$ & $12: 00-17: 00$ \\
& $17: 00-23: 00$ & $20: 00-22: 00$ \\
\hline \multirow{2}{*}{ On-peak } & $10: 00-12: 00$ & $10: 00-12: 00$ \\
& $13: 00-17: 00$ & $17: 00-20: 00$ \\
& & $22: 00-23: 00$ \\
\hline
\end{tabular}


Table 2. Examples of electricity rate tables for industrial and general customers [5].

\begin{tabular}{|c|c|c|c|c|c|}
\hline \multirow{2}{*}{ Class } & \multirow{2}{*}{$C_{\text {demand }}[\mathrm{KRW} / \mathrm{kW}]$} & \multicolumn{4}{|c|}{$C_{\text {usage }}[\mathrm{KRW} / \mathrm{kWh}]$} \\
\hline & & Period & Summer & Spring \& Fall & Winter \\
\hline Industrial service (B) & & Off-peak load & 56.2 & 56.2 & 63.2 \\
\hline High-voltage (B), & 7380 & Mid-peak load & 108.5 & 78.5 & 108.5 \\
\hline Option II & & On-peak load & 189.7 & 108.8 & 164.7 \\
\hline General service (B) & & Off-peak load & 56.1 & 56.1 & 63.1 \\
\hline High-voltage (A), & 8320 & Mid-peak load & 109.0 & 78.6 & 109.2 \\
\hline Option II & & On-peak load & 191.1 & 109.3 & 166.7 \\
\hline
\end{tabular}

\subsection{Peak Shaving and Arbitrage}

In conventional DSM, control of customer-installed ESSs for TOU tariffs is delegated to the peak shaving and arbitrage algorithms [18]. On the one hand, peak shaving saves demand charges by reducing $P_{\text {peak }}$ as it discharges ESSs in order to not exceed a previously set peak reference determined by specifications for the installed ESSs based on data purporting historical loads. The reference also considers appropriate buffers to stabilize real-time control, which primarily depends on accurate load forecasting [28,29]. On the other hand, arbitrage utilizes time-variant rates of electricity consumption $\left(C_{\text {usage }}\right)$, as introduced in Table 2. The operation charges ESSs during off-peak loads, in which $C_{\text {usage }}$ is relatively low, and discharges ESSs during mid-peak and on-peak loads, in which $C_{\text {usage }}$ is relatively high, thereby reducing usage rates. Figure 1 shows a flow-chart of the peak shaving and arbitrage operations. When the customers' load exceeds the set peak reference, ESSs preferentially discharge for peak shaving; when it does not, ESSs discharge for arbitrage if needed. Peak shaving is prioritized over arbitrage since it reduces demand charges more efficiently than arbitrage. Figure 2 shows an example of peak shaving with conventional ESS-based DSM control for a certain industrial customer's load, which takes an M-shaped pattern. The ESS's capacity is assumed to be $10 \%$ of the customer's annual peak, and the ESS is charged during the on-peak load (i.e., 1:00-5:00) and discharged when the load exceeds the peak reference (i.e., 9:00-12:00 and 14:00-17:00).

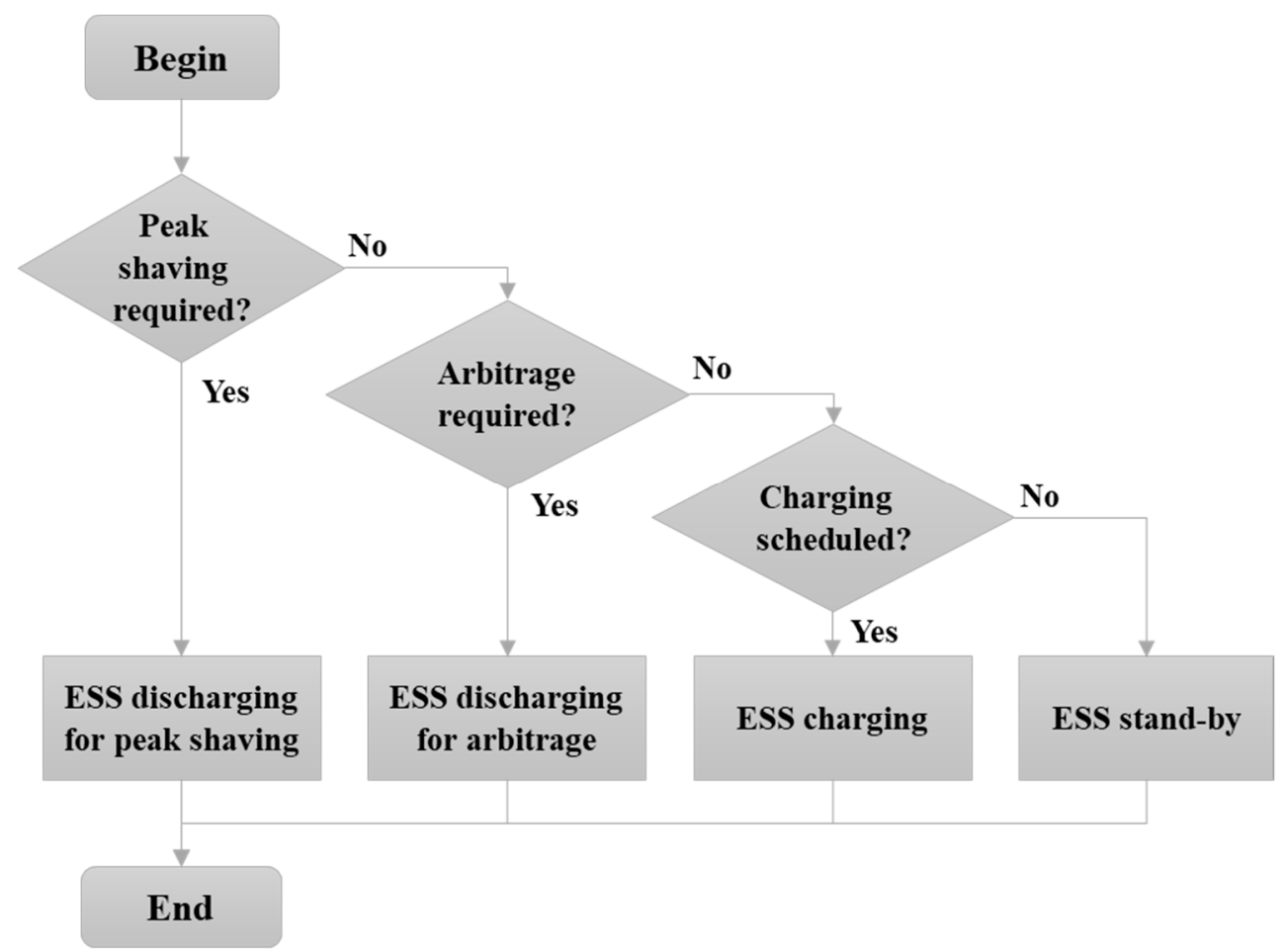

Figure 1. Flowchart of an algorithm for conventional ESS-based DSM. 

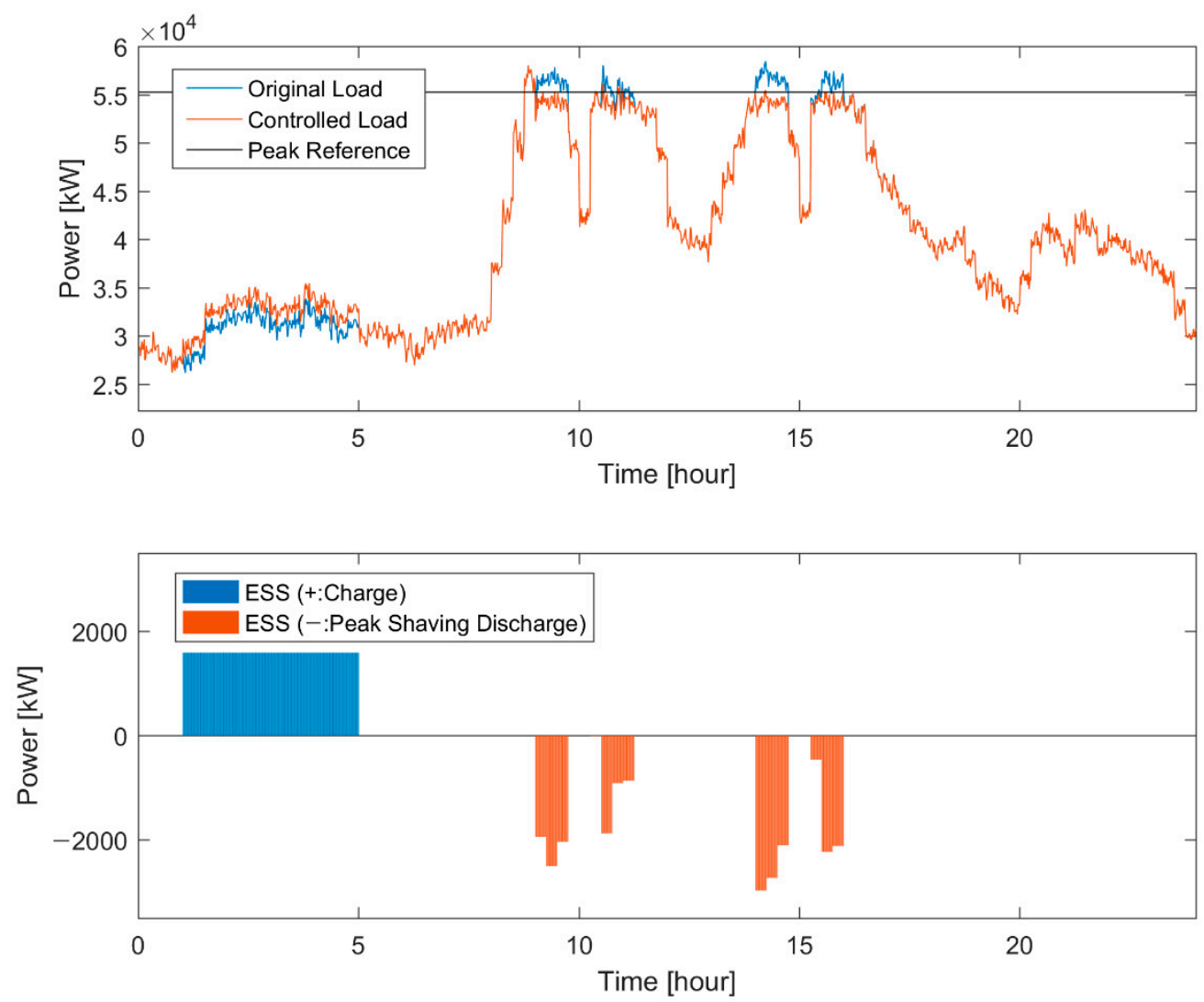

Figure 2. Example of the result of peak shaving with the conventional ESS-based DSM.

\section{Proposed ESS Operation for DSM}

\subsection{ESS-Based Maximum Demand Control}

The conventional maximum demand control is performed with specialized equipment that detects or estimates the maximum demand of the corresponding customers' load accumulated in $15 \mathrm{~min}$ and blocks parts of the loads step-by-step according to prearranged schedule when the estimated maximum demand exceeds the target demand [30,31]. By contrast, ESS-based maximum demand control activates the ESS instead of blocking the load [32].

Figure 3 demonstrates an operating principal of maximum demand control. To begin, the control mechanism always compares the accumulated current demand and the reference demand in real time within $15 \mathrm{~min}$. Once the predicted demand at the end of the $15 \mathrm{~min}$, calculated by an increasing rate of the accumulated current demand, is estimated to exceed the target demand, the ESS-based approach activates the ESS to reduce the current demand. That step allows keeping the current demand at the end of the 15 min under the target demand. The reference demand $\left(E_{R}\right)$ and predicted demand $\left(E_{P}\right)$ are calculated as:

$$
\begin{gathered}
E_{R}=E_{T} \times \frac{t}{T} \\
E_{P}=E_{C}+\frac{\Delta E}{\Delta t} \times(T-t)
\end{gathered}
$$

where $E_{T}$ is the target demand; $T$ is demand period; and $t$ is the elapsed period.

The ESS-based maximum demand control has suggested operational areas and boundaries for ESS operation as illustrated in Figure 4 [32]. The maximum line indicates a limitation of the switchgears installed by customers and consequently shows the greatest slope. The ESS-based lower boundary is the line at which the ESS can reduce demand according to its maximal discharge. The ESS-based upper boundary is generated in parallel by the upward movement of the ESS-based lower boundary, meaning that the marginal 
boundary can be controlled by the ESS. The control release line provides a guideline for the ESS about stopping its discharge; if the current demand reaches the area below the line, then the corresponding $15 \mathrm{~min}$ period does not require demand control. It is generated in parallel by the downward movement of the maximum line. However, if the current demand reaches the area below the maximum line and above the ESS-based upper boundary, then the system cannot maintain the current target demand and consequently needs to increase the target.

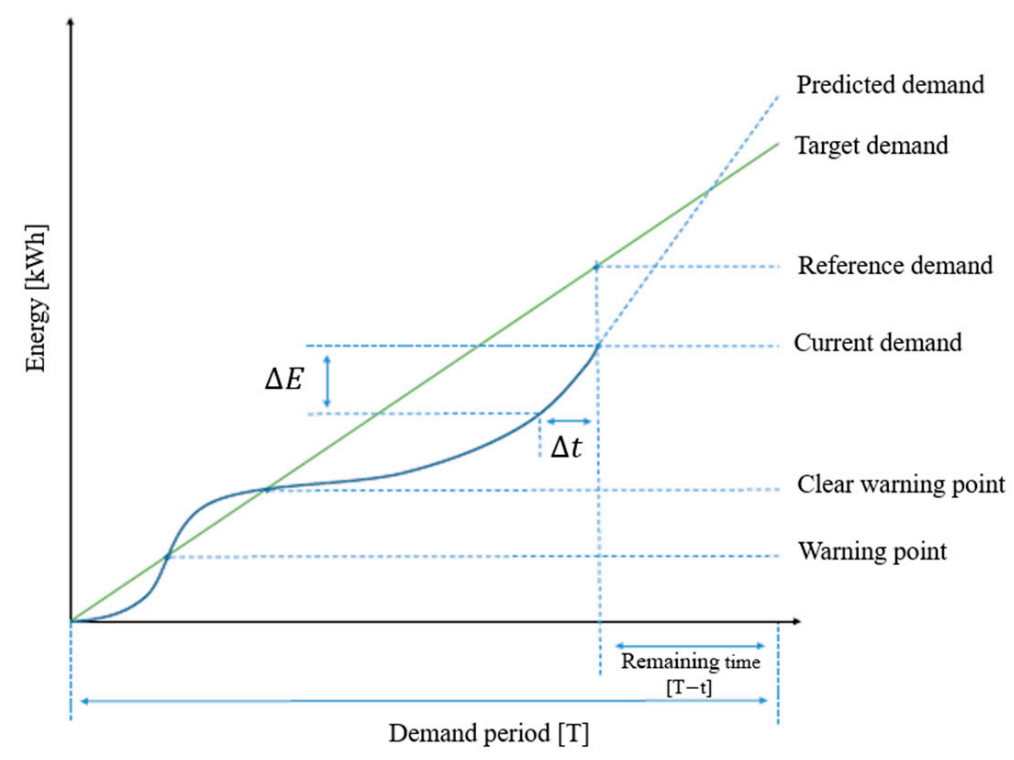

Figure 3. Principal of the maximum demand control.

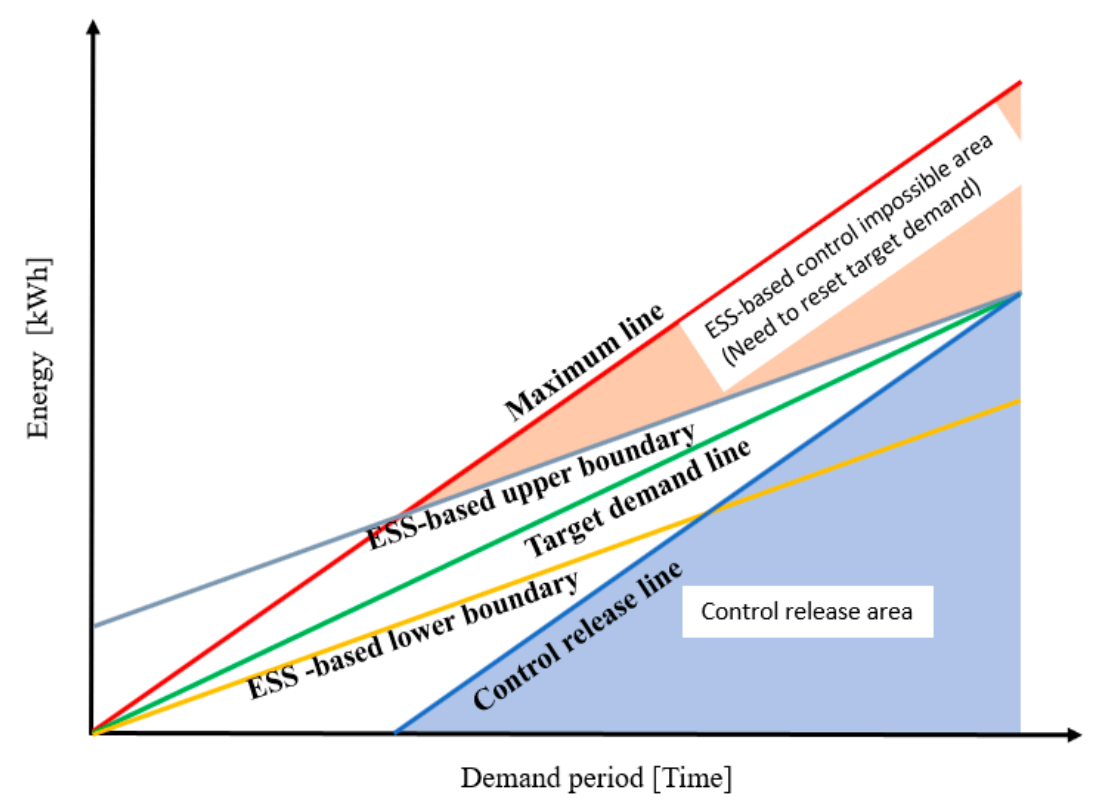

Figure 4. Operational boundaries of the ESS-based control.

\subsection{Estimation of 1-Min Load Variations}

\subsubsection{MTM-Based Estimation}

To estimate 1-min load variations within a $15 \mathrm{~min}$ period, this study adopted a probabilistic model using an MTM. The MTM indicates the probability of transitioning $\left(p_{i j}\right)$ from the current state to the next state if a change in state occurs corresponding to time [33]. Figure 5 shows the general $n \times n$ MTM; the sum of each row is 1 , whereas $p_{i j}$ is a value between 0 and 1 . 


\begin{tabular}{|c|c|c|c|c|c|c|c|c|}
\cline { 2 - 9 } \multicolumn{1}{c|}{} & $S_{1}$ & $S_{2}$ & $\cdot$ & $\cdot$ & $S_{j}$ & $\cdot$ & $\cdot$ & $S_{n}$ \\
\hline$S_{1}$ & $p_{11}$ & $p_{12}$ & $\cdot$ & $\cdot$ & $p_{1 j}$ & $\cdot$ & $\cdot$ & $p_{1 n}$ \\
\hline$S_{2}$ & $p_{21}$ & $p_{22}$ & $\cdot$ & $\cdot$ & $p_{2 j}$ & $\cdot$ & $\cdot$ & $p_{2 n}$ \\
\hline$\cdot$ & $\cdot$ & $\cdot$ & $\cdot$ & $\cdot$ & $\cdot$ & $\cdot$ & $\cdot$ & $\cdot$ \\
\hline$\cdot$ & $\cdot$ & $\cdot$ & $\cdot$ & $\cdot$ & $\cdot$ & $\cdot$ & $\cdot$ & $\cdot$ \\
\hline$S_{i}$ & $p_{i 1}$ & $p_{i 2}$ & $\cdot$ & $\cdot$ & $p_{i j}$ & $\cdot$ & $\cdot$ & $p_{i n}$ \\
\hline$\cdot$ & $\cdot$ & $\cdot$ & $\cdot$ & $\cdot$ & $\cdot$ & $\cdot$ & $\cdot$ & $\cdot$ \\
\hline$\cdot$ & $\cdot$ & $\cdot$ & $\cdot$ & $\cdot$ & $\cdot$ & $\cdot$ & $\cdot$ & $\cdot$ \\
\hline$S_{n}$ & $p_{n 1}$ & $p_{n 2}$ & $\cdot$ & $\cdot$ & $p_{n j}$ & $\cdot$ & $\cdot$ & $p_{n n}$ \\
\hline
\end{tabular}

Figure 5. General $n \times n$ MTM.

Data regarding variability $(V(t))$, generated to obtain high-resolution data within the 15-min demand period, were calculated as:

$$
V(t)=\frac{P_{1}(t)-P_{15}(t)}{P_{15, \text { peak }}}
$$

where $P_{1}(t)$ is 1-min load data; $P_{15}(t)$ is the average value of $P_{1}(t)$ in 15-min intervals; and $P_{15 \text {,peak }}$ is the peak during the corresponding $15 \mathrm{~min}$. The state of MTM $\left(S_{k}\right)$ can be determined as follows:

$$
S_{k}=V_{\min }+d(k-1), k=1,2, \ldots, m+1
$$

where $V_{\min }$ is the minimum value of data regarding variability; $m$ is the total number of gaps between states; and $d$ is a gap between states, calculated as:

$$
d=\frac{V_{\max }-V_{\min }}{m}
$$

where $V_{\max }$ is the maximum value of the data regarding variability. Once the MTM was generated, the estimation data were synthesized by first adding the accumulation to each row in the MTM and later creating lines of the cumulative probability of transition. Second, the initial current state of those lines was randomly defined. Third, the probability from the current state to the next state was generated as a random value between 0 and 1 , such that if the value is less than or equal to the value at the row of the lines of the cumulative probability of transition, then the next state is determined. That process repeats itself, and minute-by-minute data regarding variability $\left(V_{g}(t)\right)$ are estimated. Last, 1-min load data $\left(P_{1, g}(t)\right)$ are calculated as:

$$
P_{1, g}(t)=V_{g}(t) \times P_{15, \text { peak }}+P_{15}(t)
$$

\subsubsection{ANN-Based Estimation}

To estimate 1-min variations within the 15-min period, this study also used a feedforward ANN model, in which feed-forward refers to a condition in which the flow is unidirectional, and no feedback between neurons exists [27]. Figure 6 shows a general structure of the ANN model, containing three layers-input, hidden, and output-each composed of neurons. A weighted connection exists between layers, and the input layer comprises input variables. Each neuron in the hidden layer is deformed by the sum of input variables weighted by $W^{(1)}[34,35]$, and a hyperbolic tangent sigmoid function is used [27]. The 
output variables in the output layer are the sum of hidden nodes weighted by $W^{(2)}$. The ANN-based data regarding variability $\left(Y_{k, g}(t)\right)$ are calculated as:

$$
\left.Y_{k, g}(t)=W_{0 k}^{(2)}+\sum_{m=1}^{M}\left(W_{m k}^{(2)} \cdot\left(\frac{2}{1+e^{-2\left(W_{0 m}^{(1)}+\sum_{n=1}^{N} W_{n m}^{(1)} X_{n}(t)\right)}}\right)-1\right)\right)
$$

where $k$ refers to gaps within the 15 -min demand period $(k=1,2, \ldots, 15) ; M$ is the number of hidden neurons; $N$ is the number of input variables; and $W^{(1)}$ and $W^{(2)}$ are the ANN model parameters of each layer. The learning algorithm of the model minimizes the mean squared error (MSE) of the actual and generated data by adjusting parameters, $W^{(1)}$ and $W^{(2)}$. The MSE is calculated as:

$$
\operatorname{MSE}=\frac{1}{l} \sum_{t=1}^{l}\left(Y_{k, a c t u a l}(t)-Y_{k, g}(t)\right)^{2}
$$

where $l$ is the length of learning data and $Y_{k, a c t u a l}(t)$ is actual variability over $1 \mathrm{~min}$. The learning algorithm uses resilient propagation to minimize the MSE [36,37].

$$
\text { Input layer Hidden layer Output layer }
$$

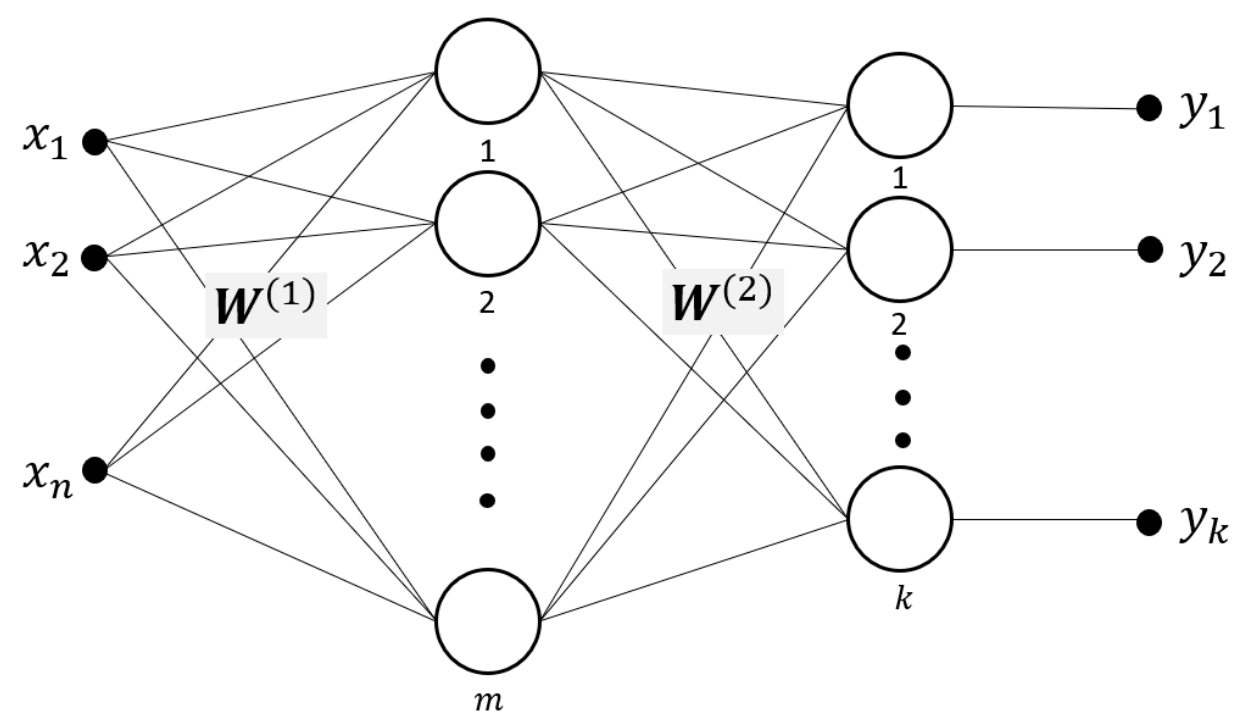

Figure 6. General structure of ANN.

Table 3 summarizes the input and output variables used in the proposed ANN-based estimation model. Last, the generated variability data are converted into 1-min generated

\begin{tabular}{|c|c|c|}
\hline Variables & & Information \\
\hline \multirow{4}{*}{ Inputs } & $P_{15}(t)$ & Variables of customers' demand during $15 \mathrm{~min}$ \\
\hline & $\operatorname{TOU}(t)$ & $\begin{array}{c}\text { Variables of the TOU tariff } \\
\text { (i.e., off-peak }=1, \text { mid-peak }=2, \text { on-peak }=3 \text { ) }\end{array}$ \\
\hline & $\operatorname{Day}(t)$ & $\begin{array}{c}\text { Variables for days of the week } \\
\text { (i.e., Mon. }=[1,0,0,0,0,0,0], \text { Tue. }=[0,1,0,0,0,0,0] \ldots \text { ) }\end{array}$ \\
\hline & Interval $(t)$ & $\begin{array}{l}\text { Variables of intervals that divide sections based on the } \\
\text { maximum and minimum values of } P(t) \\
\text { (i.e., } 0-25 \mathrm{~kW}=1,25-50 \mathrm{~kW}=2,50-75 \mathrm{~kW}=3,75-100 \mathrm{~kW}=4 \text { ) }\end{array}$ \\
\hline Outputs & $V(t)$ & 1-min variability data during the corresponding $15 \mathrm{~min}$ \\
\hline
\end{tabular}
data regarding load according to Equation (7), as in the MTM model as well.

Table 3. Configuration of training data. 


\subsubsection{Hybrid}

This study also developed a hybrid model by combining the MTM and ANN models to improve the accuracy of estimation. The estimation model showing high variability has an advantage or improving the stability of control because its generated 1-min load tends to conservatively reserve the ESS's capacity. However, greater variability could deteriorate the accuracy of the estimation of the generated data. As demonstrated in the TOU tariff structure in Section 2.1, the annual peak affecting the charge in demand is determined at either the on-peak load or the mid-peak load. Thus, the proposed hybrid model utilizes the estimation model showing greater variability to generate load profiles at the on-peak and mid-peak load times, whereas the model showing smaller variability generates load profiles at the off-peak load time. That combined approach improves both the stability of the ESS's reserved capacity for maximum demand control and the accuracy of the estimation of all generated data.

Figure 7 illustrates the development of the proposed hybrid model. In the first stage, the 1-min data regarding variability were generated according to information provided about load. Thereafter, estimating 1-min load variations over $15 \mathrm{~min}$ was performed by both the MTM and ANN-based models. The model with the greater standard deviation in variability was used to estimate the on- and mid-peak loads, whereas the model with the smaller standard deviation was used to estimate the off-peak load.

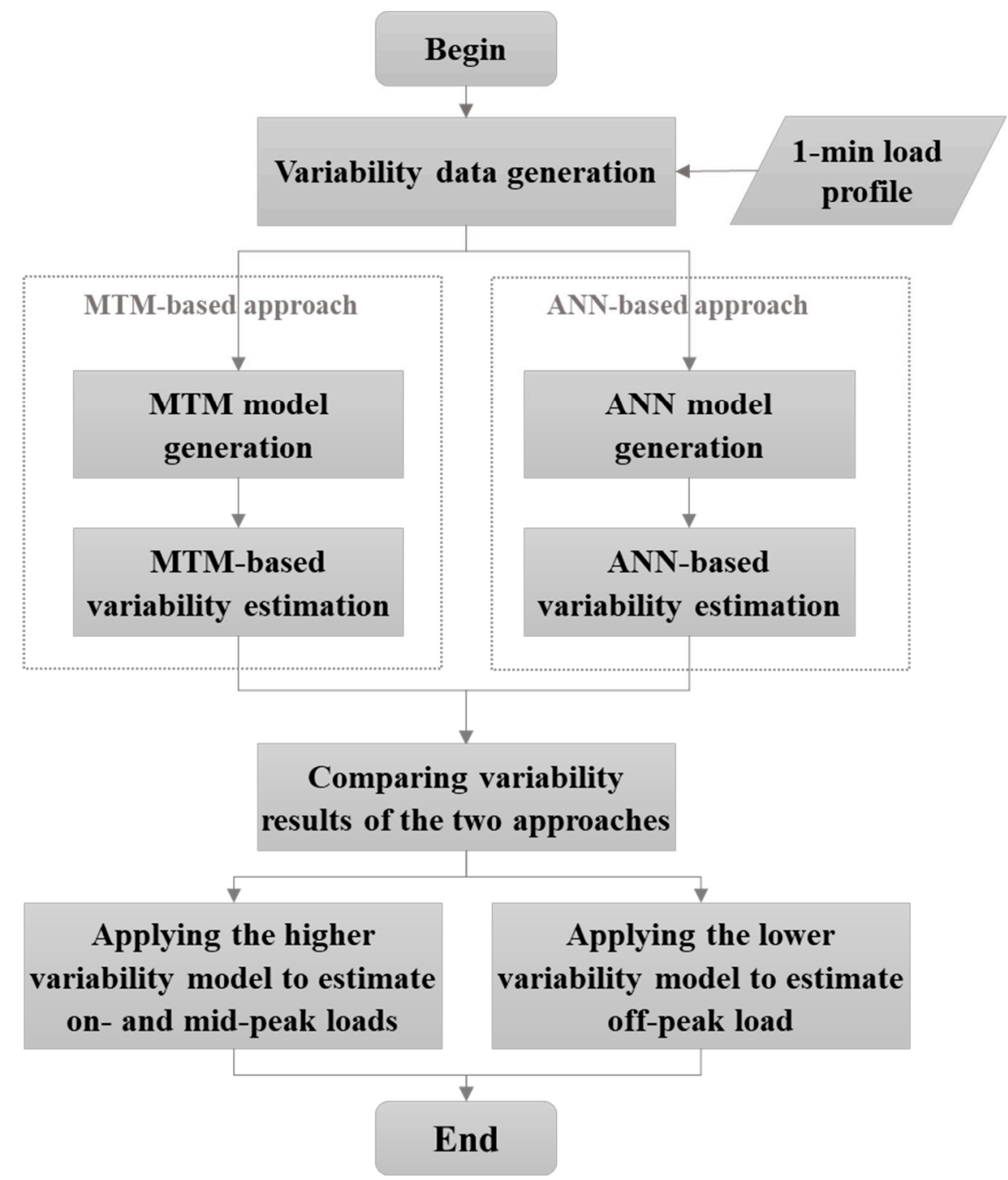

Figure 7. Development of the proposed hybrid estimation model. 


\subsection{ESS-Based DSM: A Proposal}

In turn, this study proposes a new operational method for customer-installed ESSs for efficient DSM that can offer real-time maximum demand control within 15-min periods. The method effectively applies ESS-based maximum demand control to conventional peak shaving by:

- Step 1: Generating synthetic load profiles including minute-by-minute load fluctuations for an entire year using the proposed hybrid estimation model described in Section 3.2.3;

- Step 2: Calculating optimal capacity within the ESS for controlling maximum demand, as described in Section 3.1, based on the generated 1-min synthetic load profiles; and

- Step 3: Establishing a new peak reference for simultaneous peak shaving and maximum demand control.

This approach improves the effect of peak shaving by controlling variability within 15 min during the real-time operation of the ESS.

Figure 8 presents a flow-chart of the proposed ESS-based DSM method. Top priority is assigned to ESS-based maximum demand control, which allows simultaneously operating with peak shaving during days with annual peaks higher than the newly established peak reference. The new reference can be aggressively decreased to improve peak shaving's effect compared with the conventional peak reference, which includes buffers to stabilize control due to the accuracy of load forecasting as introduced in Section 2.2. If those annual peaks can be controlled by the peak shaving operation with the conventional peak reference, then maximum demand control become unnecessary. If annual peaks are not showing, then the ESS performs arbitrage according to daily charging and discharging schedules similar to the conventional ESS-based DSM, as described in Figure 1.

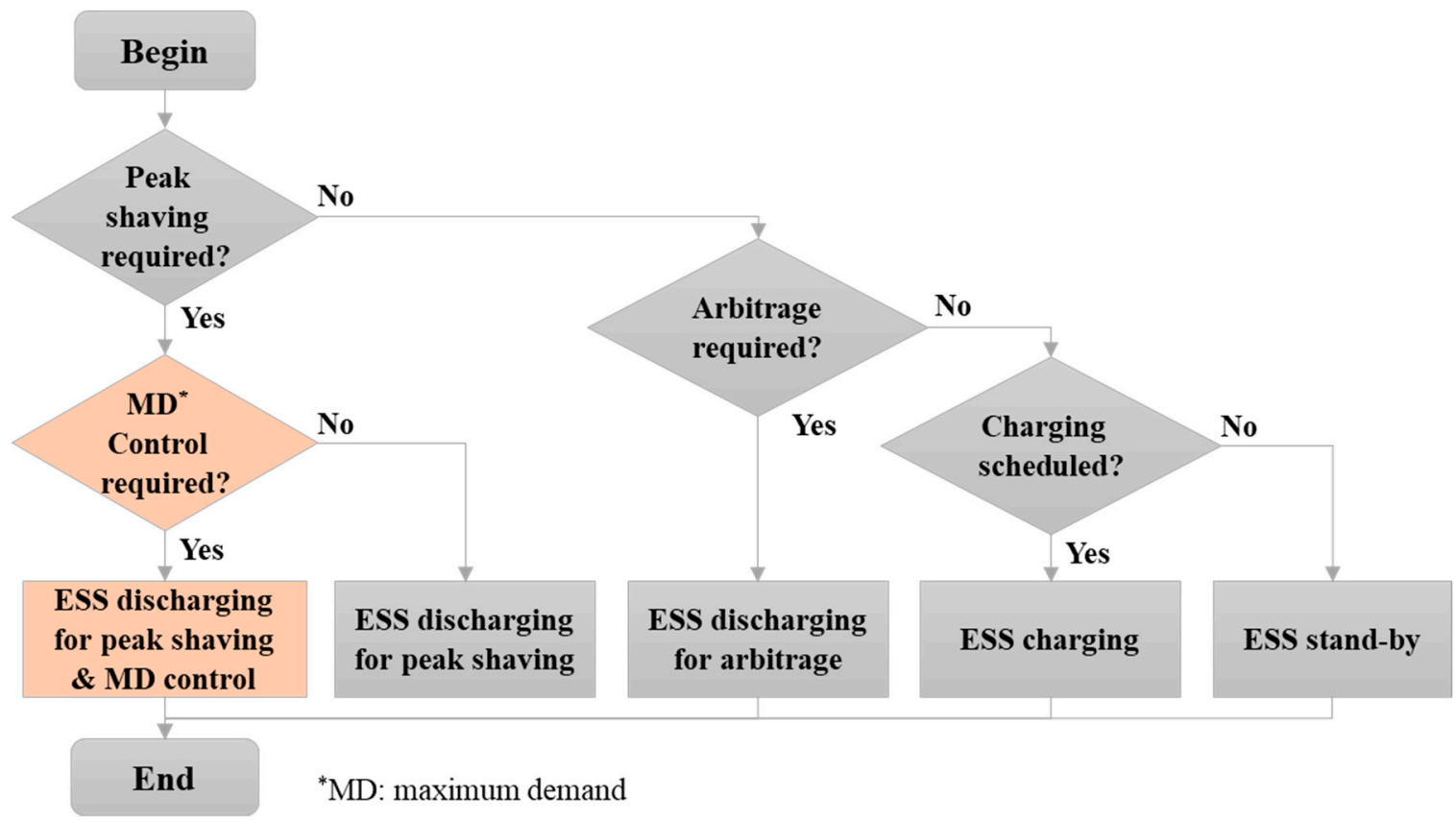

Figure 8. Flowchart of the proposed ESS-based DSM algorithm.

Figure 9 shows an example of the simultaneous operation of peak shaving and maximum demand control. The customer's load and ESS specification are identical to the case in Figure 2, although the proposed DSM algorithm is added. The proposed peak reference for peak shaving is established as $54,169 \mathrm{~kW}$, for a decrease of $8 \mathrm{~kW}$ from the conventional peak reference, $54,177 \mathrm{~kW}$. That result indicates additional ESS discharges for maximum demand control during several 15-min periods while ESS is discharged for peak shaving (i.e., 9:00-12:00 and 14:00-17:00). 

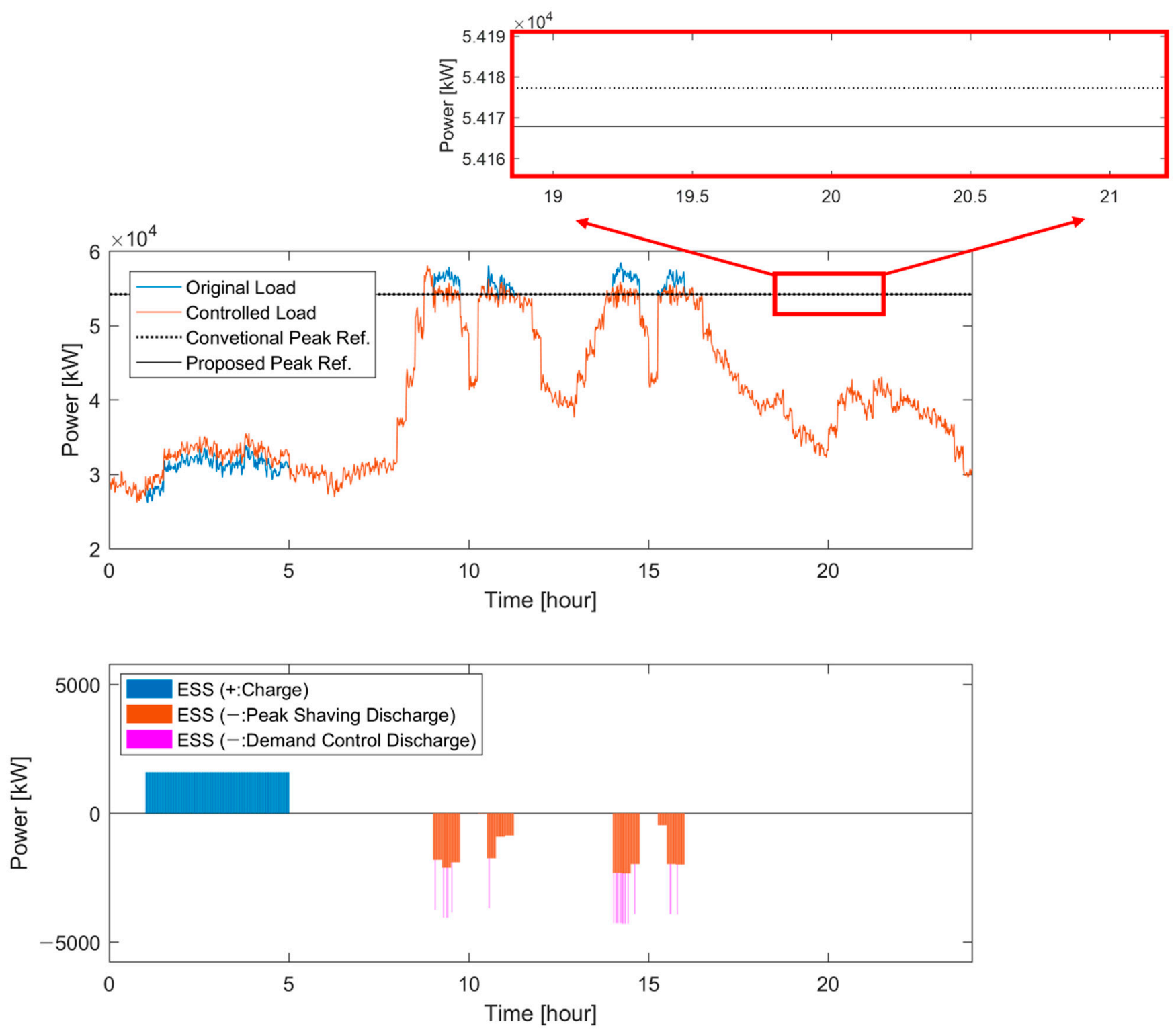

Figure 9. Example of the result of peak shaving with the proposed ESS-based DSM.

\section{Simulation}

\subsection{Data}

The simulation to verify the proposed ESS-based DSM operation utilizes 15-min load profiles accumulated by industrial and general customers using South Korea's TOU tariff from 1 January to 31 December 2016. Figure 10 shows daily patterns of those profiles, which are normalized by their annual peaks for effective comparison. The daily loads of manufacturing industries (i.e., Customers $\mathrm{A}$ and $\mathrm{B}$ ) show an $\mathrm{M}$-shaped pattern in Figure 10a; the TOU tariff structure of Industrial service (B) High-voltage (B), Option II, is applied to those two customers. By contrast, the daily loads of commercial buildings (i.e., Customers $C$ and D) show a square wave-shaped pattern in Figure 10b, and General service (B) High-voltage (A), Option II, is applied.

The 1-min customer load profiles are exceedingly limited compared with the 15-min load profiles. To estimate 1-min load variations, this study used the 1-min load profiles of Customer A measured across three weeks. Data from first 2-week period (i.e., 20,160 samples) were applied to develop the estimation model, whereas data from the last week (i.e., 10,080 samples) were used to verify the developed model. 


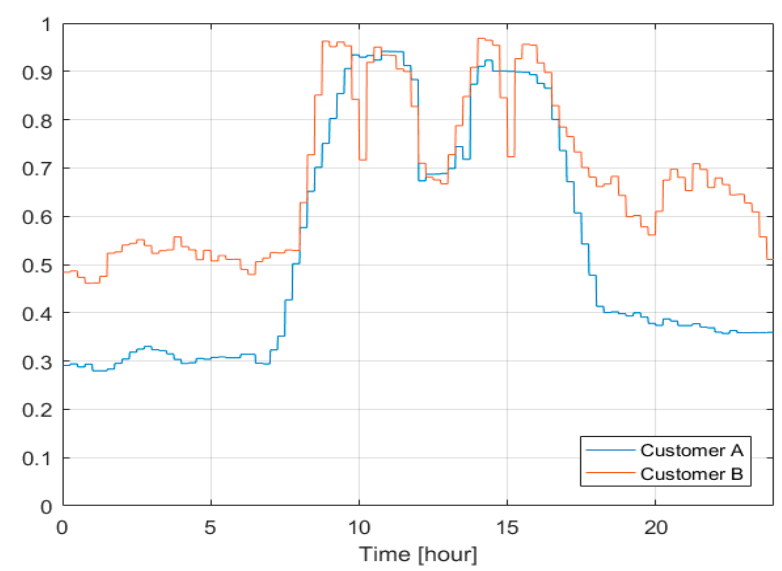

(a) Industrial customers

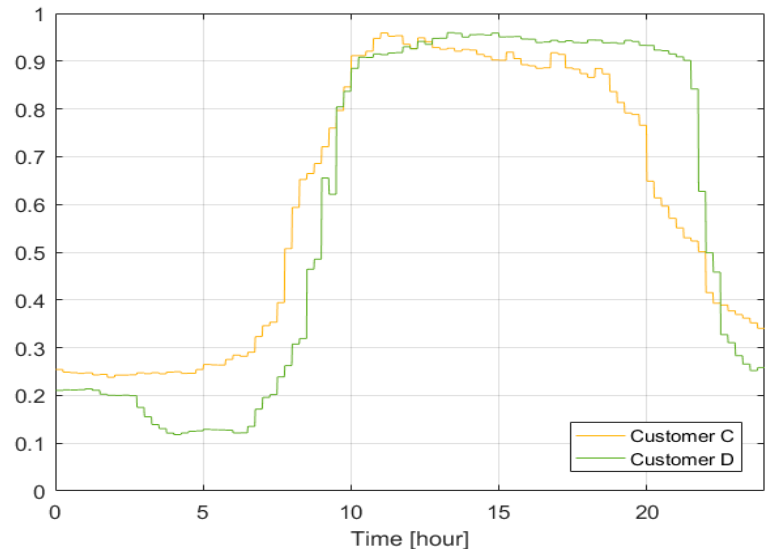

(b) General customers

Figure 10. Normalized load profiles of customers at their annual peak day: (a) industrial Customer A and B with an M-shaped pattern, and (b) general Customer C and D with a squared wave-shaped pattern.

\subsection{Verification of Estimating 1-Min Load Variations}

To verify the proposed estimation models for 1-min load variations, this study conducted a K-S test, which verifies statistical similarity between generated and actual datasets [38]. The K-S test integral (KSI) denoting the sum of differences in the cumulative distribution function $(\mathrm{CDF})$ of the two datasets is calculated as [39]:

$$
\operatorname{KSI}(\%)=100 \frac{\int_{x_{\min }}^{x_{\max }} D_{n} d x}{a_{c}}
$$

where $x_{\text {max }}$ and $x_{\text {min }}$ are the maximum and minimum values of data, respectively; $D_{n}$ is the differences between the CDF of the actual and generated datasets; and $a_{c}$ indicates the critical area, which is calculated as:

$$
a_{c}=V_{c} \times\left(x_{\max }-x_{\min }\right)
$$

where $V_{c}$ is a threshold with a $99 \%$ confidence interval. OVER denotes the statistical similarity of two datasets when the difference in CDF between them exceeds the threshold. That value is calculated as:

$$
\operatorname{OVER}(\%)=100 \frac{\int_{x_{\min }}^{x_{\max }} \operatorname{aux} d x}{a_{c}}
$$

where, aux is a value that exceeds the threshold and is calculated as:

$$
a u x= \begin{cases}D_{n}-V_{c}, & \text { if } D_{n}>V_{c} \\ 0, & \text { if } D_{n} \leq V_{c}\end{cases}
$$

Figure 11 shows daily 1-min load profiles of Customer A estimated by the proposed MTM, ANN, and hybrid models as well as measured load profiles. Because the standard deviation of the estimated 1-min variations of the MTM and ANN models were 0.0110 and 0.0161, respectively, the hybrid model was developed by applying the MTM model, which showed lower variability, to estimate the off-peak loads while applying the ANN model, which showed higher variability, to estimate the on- and mid-peak loads. The standard deviation of the hybrid model was 0.0140 , which was the standard deviation closet to the measured data, 0.0134 .

Figure 12 shows the CDFs and K-S statistics of the estimation results of the MTM, ANN, and hybrid models, whereas Table 4 compares KSI and OVER values of the estimation results. The hybrid model indicated a low KSI value and 0 OVER compared to the MTM 
and ANN estimations. Those results verify the improved estimation performance of the hybrid model.
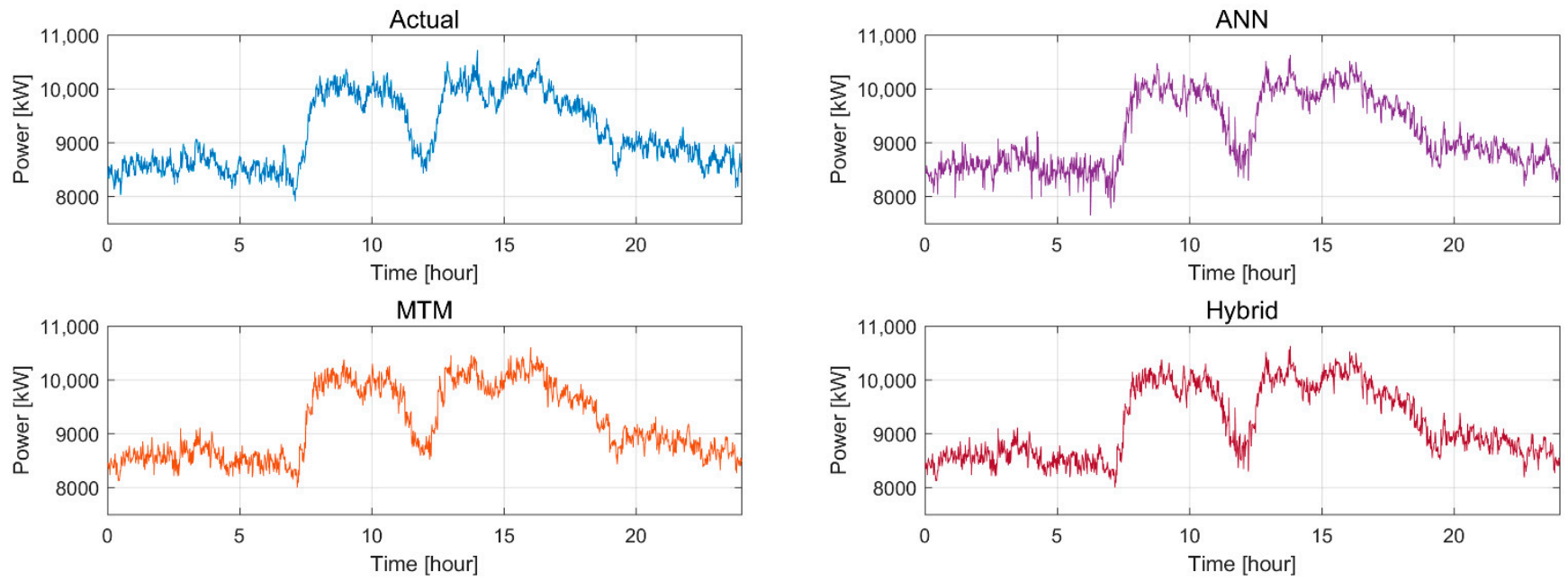

Figure 11. Daily 1-min load profiles of Customer A on the measurement and estimation results of the MTM, ANN, and hybrid models.

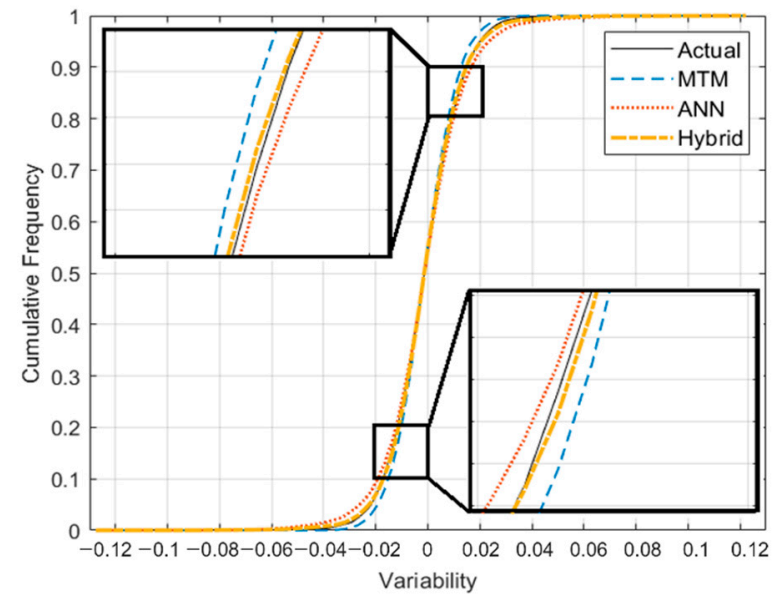

(a) $\mathrm{CDF}$

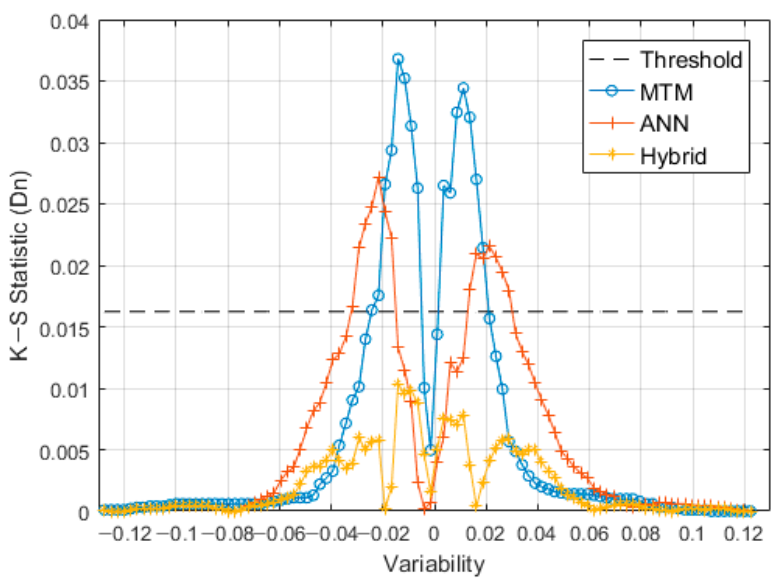

(b) K-S statistic (Dn)

Figure 12. Estimation results of the MTM, ANN, and hybrid models: (a) CDF and (b) K-S statistic (Dn).

Table 4. Estimated KSI and OVER of results of the MTM, ANN, and hybrid models.

\begin{tabular}{cccc}
\hline K-S Test & MTM & ANN & Hybrid \\
\hline KSI $(\%)$ & 37.1217 & 36.0646 & 13.2477 \\
OVER $(\%)$ & 10.8233 & 4.4234 & 0 \\
\hline
\end{tabular}

\subsection{Result of the Simulation of the Proposed ESS-Based DSM}

The proposed ESS-based DSM algorithm was simulated during the entire year for four customers: Customers A, B, C, and D. For the simulations, the ESS capacity of each customer was assumed to be $10 \%$ of each annual peak with 1 C-rate capability of charging and discharging. The charging and discharging efficiencies of the ESS were assumed to be $91 \%$ and $99 \%$, respectively [10]. Consequently, round-trip efficiency was calculated as approximately $90 \%$. For the reserved capacity of ESS-based maximum demand control, 1-min variations of the 15-min load profiles of customers were estimated with the hybrid model developed in Section 4.2. Figure 13 shows the estimated results of 1-min synthetic load profiles for Customers A-D on the same days in Figure 10. 


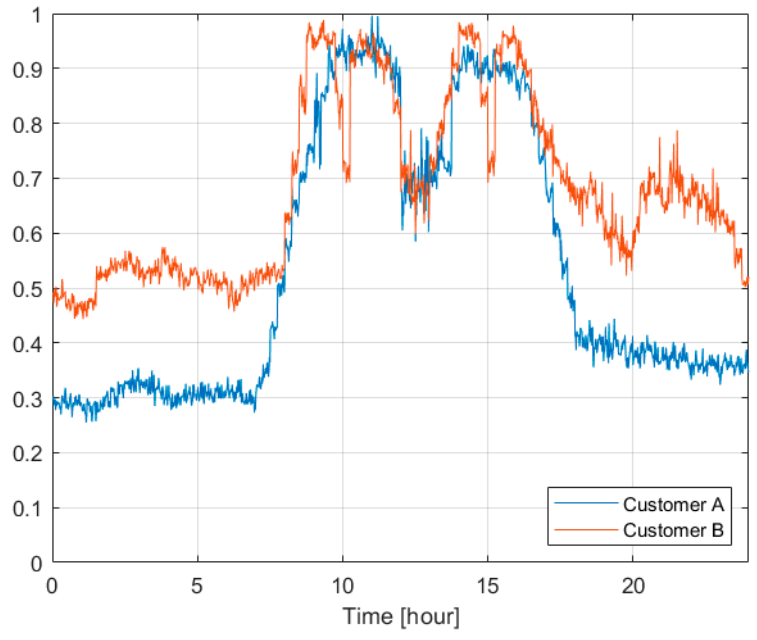

(a) Industrial customers

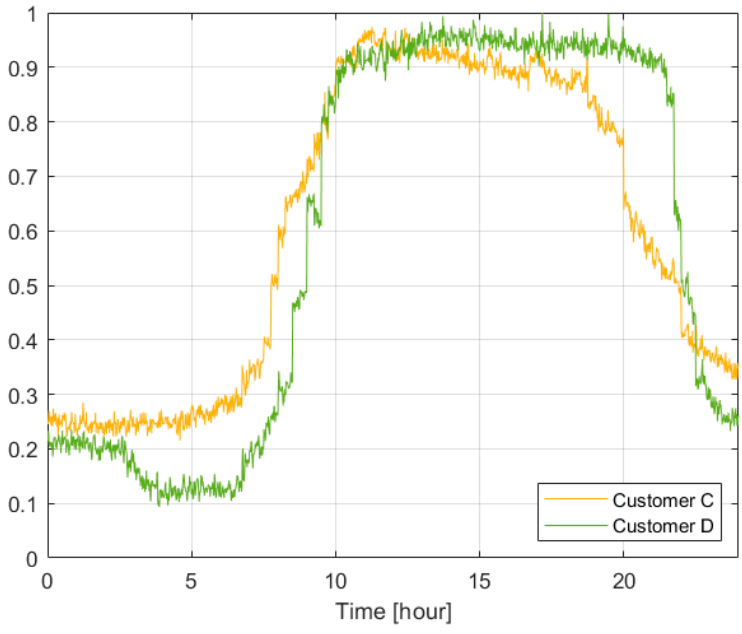

(b) General customers

Figure 13. 1-min synthetic load profiles estimated by the proposed hybrid model: (a) Customers A and B and (b) Customers C and D.

The simulation results were compared according to a proposed parameter of feasibility analysis, benefit per battery (BPB), calculated as:

$$
\mathrm{BPB}=\left(C_{\text {original }}-C_{D S M}\right) / S_{B A T}
$$

where $C_{\text {original }}$ is the annual electricity cost of the corresponding customer calculated by applying the original load profiles to Equation (1); $C_{D S M}$ is the annual electricity cost, including savings from the ESS-based DSM; and $S_{B A T}$ is the corresponding battery capacity.

Table 5 summarizes the simulation results of the proposed ESS-based DSM operations compared with the conventional ESS-based DSM approaches described in Section 2.2 for Customers A-D. For all customers, the proposed algorithm showed improved performance due to increased BPBs with decreased peak references from peak shaving. In addition, the increased BPB was higher for Customers A and B, at +21.4 and $+146.7(\mathrm{KRW} / \mathrm{kWh})$ respectively, compared with that of Customers $\mathrm{C}$ and $\mathrm{D}$, which were +7.7 and $+4.2(\mathrm{KRW} / \mathrm{kWh})$, also respectively. That difference indicates that the proposed method is more effective for the M-shaped daily load patterns than the square wave-shaped patterns.

Table 5. Simulation results of the proposed ESS-based DSM for Customers A-D.

\begin{tabular}{cccc}
\hline Customer & ESS-Based DSM & Peak Ref. [kW] & BPB [KRW/kWh] \\
\hline \multirow{2}{*}{ Customer A } & Conventional & $49,589.1$ & $82,727.5$ \\
\cline { 2 - 4 } & Proposed & $49,587.9$ & $82,748.9(+21.4)$ \\
\hline \multirow{2}{*}{ Customer B } & Conventional & $54,177.3$ & $79,893.0$ \\
\cline { 2 - 4 } & Proposed & $54,167.9$ & $80,039.7(+146.7)$ \\
\hline \multirow{2}{*}{ Customer C } & Conventional & 2288.42 & $74,452.6$ \\
\cline { 2 - 4 } & Proposed & 2288.40 & $74,460.3(+7.7)$ \\
\hline \multirow{2}{*}{ Customer D } & Conventional & 4232.95 & $62,652.3$ \\
\cline { 2 - 4 } & Proposed & 4232.93 & $62,656.5(+4.2)$ \\
\hline
\end{tabular}

\section{Conclusions}

As a result of this study, we proposed an ESS-based DSM method that developed by applying ESS-based maximum demand control to the conventional DSM operations of customer-installed ESSs. The new method enables the simultaneous real-time control of load variations within 15 -min periods during conventional peak shaving, which is opti- 
mized by 15-min accumulated load profiles and needs to consider buffers for establishing its peak reference due to the limitation of being unable to control variability in 15-min periods. This study validated the proposed ESS-based DSM method via simulation using load profiles accumulated from four industrial and general customers under South Korea's TOU tariff structure. The simulation compared the conventional and proposed ESS-based DSM for all four customers using a proposed feasibility parameter, BPB, calculated by annual savings with the DSM application based on battery size. The simulation revealed that the proposed method improved the performance for all customers and performed better for M-shaped daily load patterns (i.e., Customers A and B) than square wave-shaped patterns (i.e., Customers C and D).

This study also proposed a hybrid method to estimate 1-min variations in 15-min load profiles of customers to reserve an ESS's capacity for maximum demand control. First, we developed two estimation models based on the MTM and ANN approaches. The proposed hybrid model applies the model with the higher variability in estimating the load profiles on mid-and on-peak loads, whereas the model showing the lower variability was used to estimate off-peak loads. The 1-min load profiles measured from an industrial customer (i.e., Customer A) for 3 weeks were used for model development (i.e., 2 weeks) and validation (i.e., 1 week). The developed ANN-based estimation model showed greater variability, whereas the MTM-based model showed lower variability. The hybrid method combines the ANN approach for estimating mid-and on-peak loads and the MTM approach for estimating off-peak loads. The K-S test results using KSI and OVER indicated the improved estimation of the hybrid method compared with the MTM- and ANN-based estimations.

Our work to improve ESS-based DSM algorithms more broadly seeks to increase the feasibility of customer-installed ESSs and, in turn, accelerate the widespread use of ESSs. To that end, future studies should apply the proposed ESS-based methods of controlling variability to effectively control the variability of RESs such as solar and wind, which have sporadic output characteristics. In addition, the proposed approach to generating synthetic high-resolution signals can be used to estimate variability in the generation of those RESs.

Author Contributions: K.B.H. mainly performed the algorithm development and simulations. J.J. contributed to algorithm development and data acquisition. B.O.K. provided the guidelines of this research and assisted as an advising professor. All authors have read and agreed to the published version of the manuscript.

Funding: This research was supported by Dong-A University.

Data Availability Statement: Not applied.

Conflicts of Interest: The authors declare no conflict of interest.

\section{References}

1. Moslehi, K.; Kumar, R. A Reliability Perspective of the Smart Grid. IEEE Trans. Smart Grid 2010, 1, 57-64. [CrossRef]

2. Kodaira, D.; Yu, B.; Jung, W.; Han, S. Optimized ESS Operation for Peak Shaving based on Probabilistic Load Prediction. In Proceedings of the 2018 IEEE Innovative Smart Grid Technologies-Asia (ISGT Asia), Singapore, 22-25 May 2018; pp. 1199-1203.

3. Anjana, S.P.; Angel, T.S. Intelligent demand side management for residential users in a smart micro-grid. In Proceedings of the 2017 International Conference on Technological Advancements in Power and Energy (TAP Energy), Kollam, India, 21-23 December 2017; pp. 1-5.

4. Kim, S.H.; Lee, G.; Shin, Y.J. Economical Energy Storage Systems Scheduling Based on Load Forecasting Using Deep Learning. In Proceedings of the 2019 IEEE International Conference on Big Data and Smart Computing (BigComp), Kyoto, Japan, 27 Feburary-2 March 2019; pp. 1-7.

5. Korea Electric Power Corp. Electrical Supply Terms and Conditions. Available online: http://cyber.kepco.co.kr (accessed on 19 October 2020).

6. Strbac, G. Demand side management: Benefits and challenges. Energy Policy 2008, 36, 4419-4426. [CrossRef]

7. Gelazanskas, L.; Gamage, K.A.A. Demand side management in smart grid: A review and proposals for future direction. Sustain. Cities Soc. 2014, 11, 20-30. [CrossRef]

8. Dharani, R.; Balasubramonian, M.; Babu, T.S.; Nastasi, B. Load Shifting and Peak Clipping for Reducing Energy Consumption in an Indian University Campus. Energies 2021, 14, 558. [CrossRef]

9. Warren, P. A review of demand-side management policy in the UK. Renew. Sustain. Energy Rev. 2014, 29, 941-951. [CrossRef] 
10. Kang, B.O.; Lee, M.; Kim, Y.; Jung, J. Economic analysis of a customer-installed energy storage system for both self-saving operation and demand response program participation in South Korea. Renew. Sustain. Energy Rev. 2018, 94, 69-83. [CrossRef]

11. Leadbetter, J.; Swan, L. Battery storage system for residential electricity peak demand shaving. Energy Build 2012, 55, 685-692. [CrossRef]

12. Martins, R.; Hesse, H.C.; Jungbauer, J.; Vorbuchner, T.; Musilek, P. Optimal Component Sizing for Peak Shaving in Battery Energy Storage System for Industrial Applications. Energies 2018, 11, 2048. [CrossRef]

13. De Salis, R.T.; Clarke, A.; Wang, Z.; Moyne, J.; Tilbury, D.M. Energy storage control for peak shaving in a single building 2014. In Proceedings of the IEEE PES General Meeting I Conference \& Exposition, National Harbor, MD, USA, 27-31 July 2014; pp. 1-5.

14. Kim, S.; Kim, J.; Cho, K.; Byeon, G. Optimal operation control for multiple BESSs of a large-scale customer under time-based pricing. IEEE Trans. Power Syst. 2018, 33, 803-816. [CrossRef]

15. Kodaira, D.; Jung, W.; Han, S. Optimal Energy Storage System Operation for Peak Reduction in a Distribution Network Using a Prediction Interval. IEEE Trans. Smart Grid 2020, 11, 2208-2217. [CrossRef]

16. Yoon, Y.; Kim, Y.-H. Charge Scheduling of an Energy Storage System under Time-of-Use Pricing and a Demand Charge. Sci. World J. 2014, 2014, 937329. [CrossRef] [PubMed]

17. Lee, W.; Kang, B.O.; Jung, J. Development of energy storage system scheduling algorithm for simultaneous self-consumption and demand response program participation in South Korea. Energy 2018, 161, 963-973. [CrossRef]

18. Jeong, H.C.; Jung, J.; Kang, B.O. Development of Operational Strategies of Energy Storage System Using Classification of Customer Load Profiles under Time-of-Use Tariffs in South Korea. Energies 2020, 13, 1723. [CrossRef]

19. Parra, D.; Gillott, M.; Norman, S.A.; Walker, G.S. Optimum community energy storage system for PV energy time-shift. Appl. Energy 2013, 137, 576-587. [CrossRef]

20. Beaudin, M.; Zareipour, H.; Schellenberglabe, A.; Rosehart, W. Energy storage for mitigating the variability of renewable electricity sources: An updated review. Energy Sustain. Dev. 2010, 14, 302-314. [CrossRef]

21. Hussain, S.; Ahmed, M.A.; Kim, Y.-C. Efficient Power Management Algorithm Based on Fuzzy Logic Inference for Electric Vehicles Parking Lot. IEEE Access 2019, 7, 65467-65485. [CrossRef]

22. Hussain, S.; Ahmed, M.A.; Lee, K.-B.; Kim, Y.-C. Fuzzy Logic Weight Based Charging Scheme for Optimal Distribution of Charging Power among Electric Vehicles in a Parking Lot. Energies 2020, 13, 3119. [CrossRef]

23. Hussain, S.; Lee, K.-B.; Ahmed, M.A.; Hayes, B.; Kim, Y.-C. Two-Stage Fuzzy Logic Inference Algorithm for Maximizing the Quality of Performance under the Operational Constraints of Power Grid in Electric Vehicle Parking Lots. Energies 2020, 13, 4634. [CrossRef]

24. Ngoko, B.; Sugihara, H.; Funaki, T. Synthetic generation of high temporal resolution solar radiation data using Markov models. Sol. Energy 2014, 103, 160-170. [CrossRef]

25. Kang, B.O.; Tam, K.-S. A new characterization and classification method for daily sky conditions based on ground-based solar irradiance measurement data. Sol. Energy 2013, 94, 102-118. [CrossRef]

26. Pillai, G.G.; Putrus, G.A.; Pearsall, N.M. Generation of synthetic benchmark electrical load profiles using publicly available load and weather data. Int. J. Electr. Power 2014, 61, 1-10. [CrossRef]

27. Ekonomou, L.; Oikonomou, D. Application and comparison of several artificial neural networks for forecasting the Hellenic daily electricity demand load. In Proceedings of the 7th WSEAS International Conference on Artificial Intelligence, Knowledge Engineering and Data Bases, Cairo, Egypt, 29-31 December 2008; pp. 67-71.

28. Chua, K.H.; Lim, Y.S.; Morris, S. A novel fuzzy control algorithm for reducing the peak demands using energy storage system. Energy 2017, 122, 265-273. [CrossRef]

29. Castellanos, J.D.A.; Rajan, H.D.V.; Rohde, A.K.; Denhof, D.; Freitag, M. Design and simulation of a control algorithm for peak-load shaving using vehicle to grid technology. SN Appl. Sci. 2019, 1, 951. [CrossRef]

30. Jorge, H.; Martins, A.; Gomes, A. Maximum demand control: A survey and comparative evaluation of different methods. IEEE Trans. Power Syst. 1993, 8, 1013-1019. [CrossRef]

31. Hoffman, A.J. Peak demand control in commercial buildings with target peak adjustment based on load forecasting. In Proceedings of the 1998 IEEE International Conference on Control Applications (Cat. No. 98CH36104), Trieste, Italy, 4 September 1998; Volume 2, pp. 1292-1296.

32. Han, K.B.; Jeong, H.C.; Kang, B.O. Maximum Demand Control Method using Customer-Installed Energy Storage System. In Proceedings of the 2018 Korean Institute of Electrical Engineers Summer Conference, Pyeongchang, Korea, 11-13 July 2018; Volume 7, pp. 31-32.

33. Sahin, A.D.; Sen, Z. First-order Markov chain approach to wind speed modeling. J. Wind Engng. Ind. Aerodyn. 2001, 89, 263-269. [CrossRef]

34. Ryu, S.; Noh, J.; Kim, H. Deep Neural Network Based Demand Side Short Term Load Forecasting. Energies 2017, 10, 3. [CrossRef]

35. Kong, J.; Jufri, F.H.; Kang, B.O.; Jung, J. Development of ESS SchedulingAlgorithm to Maximize the Potential Profitability of PV Generation Supplier in South Korea. J. Electr. Eng. Technol. 2018, 13, 2227-2235.

36. Riedmiller, M.; Braun, H. A direct adaptive method for faster backpropagation learning: The RPROP algorithm. In Proceedings of the IEEE International Conference on Neural Networks, San Francisco, CA, USA, 28 Mrach-1 April 1993; pp. 586-591.

37. Igel, C.; Hüsken, M. Improving the Rprop Learning Algorithm. In Proceedings of the Second International ICSC Symposium on Neural Computation (NC 2000), Berlin, Germany, 23-26 May 2000. 
38. Espinar, B.; Ramírez, L.; Drews, A.; Beyer, H.G.; Zarzalejo, L.F.; Polo, J.; Martín, L. Analysis of different comparison parameters applied to solar radiation data from satellite and German radiometric stations. Sol. Energy 2009, 83, 118-125. [CrossRef]

39. Massey, F.J. The Kolmogorov-Smirnov test for goodness of fit. J. Am. Stat. Assoc. 1951, 46, 68-78. [CrossRef] 